\title{
COMMENTARY
}

\section{A new look at renal dysfunction in the cirrhotic patient}

\author{
Claire Francoz and François Durand* \\ See related research by Nadim et al., http://ccforum.com/content/16/1/R23
}

\begin{abstract}
Hepatorenal syndrome (HRS) is a pre-renal azotemialike acute renal failure occurring in patients with end-stage cirrhosis. HRS results from arteriolar vasodilatation, arteriolar underfilling, and intense renal vasoconstriction. By definition, it is not responsive to volume expansion, and the prognosis is especially poor even with the use of terlipressin or albumin dialysis or both. It may be difficult, on the basis of the current criteria, to clearly differentiate HRS from other causes of acute renal failure in cirrhosis. In addition, patients with HRS frequently have underlying chronic kidney changes that may not be reversible after transplantation. In the previous issue of Critical Care, a group of experts proposed a new classification of acute, acute-on-chronic, or chronic renal impairment in cirrhosis on the basis of the RIFLE (Risk, Injury, Failure, Loss, and End-stage kidney disease) criteria. The group proposed the term 'hepatorenal disorder' to define patients with advanced cirrhosis and kidney dysfunction at an earlier stage, regardless of the mechanisms. As stated by the authors, more data are needed to clearly identify, by non-invasive means, those with a potential for improvement with liver transplantation and those who can undergo a combined liver and kidney transplantation.
\end{abstract}

Cirrhosis is characterized by circulatory changes corresponding to a hyperkinetic state with arterial vasodilatation, decreased systemic vascular resistance, and increased cardiac output [1]. Hyperkinetic state and vasodilatation worsen in parallel with the deterioration in liver function. In patients with end-stage cirrhosis,

*Correspondence: francois.durand@bjn.aphp.fr

Hepatology and Liver Intensive Care, Hospital Beaujon, University Paris VII Denis Diderot, INSERM U773, CRB3, 100 Boulevard du Général Leclerc, 92110, Clichy, France arteriolar vasodilatation is no longer compensated by an increase in cardiac output, resulting in a state of arterial underfilling [2,3]. Arterial underfilling, in turn, results in the activation of vasoconstrictor systems, which causes intense intrarenal vasoconstriction and a marked decrease in glomerular filtration rate (GFR) and eventually leads to hepatorenal syndrome (HRS). The increase in creatinine can be abrupt (type I HRS) or follow a more progressive course (type II HRS) [4].

A first set of criteria had been proposed in the mid-'90s to better differentiate HRS from other causes of acute renal failure in cirrhosis, the absence of improvement with volume expansion being central in the definition of HRS [5]. However, these criteria proved to be too restrictive. For instance, ongoing bacterial infection was considered an exclusion criterion although experience shows that HRS frequently is triggered by infections [3]. The diagnostic criteria were revisited in 2007 in order to be less restrictive [6]. However, these criteria still have some limitations. Firstly, it has been shown that a substantial proportion of patients who are undergoing transjugular renal biopsy and who have a clinical diagnosis of HRS do have intrinsic kidney changes, especially tubulointerstitial injury resulting from either comorbidities or chronic ischemia [7]. Secondly, the limit of a creatinine level of more than $1.5 \mathrm{mg} / \mathrm{dL}$ to define HRS may be inappropriate. Indeed, owing to muscle wasting, some cirrhotic patients with a serum creatinine level of below $1 \mathrm{mg} / \mathrm{dL}$ may already have a marked decrease in true GFR $[8,9]$.

In the previous issue of Critical Care, a group of experts, including not only hepatologists but also nephrologists and intensivists, reported the results of a workshop aimed at reviewing current knowledge in the field of HRS and proposing new classifications, based on the widely used RIFLE (Risk, Injury, Failure, Loss, and Endstage kidney disease) criteria, of all forms of renal impairment in cirrhosis $[1,10]$. The group proposed the term 'hepatorenal disorder' to define any kind of kidney disease that is functional or structural in nature in patients with cirrhosis [1]. Accordingly, HRS belongs to the 'hepatorenal disorders'. Acute kidney injury is 
considered at an earlier stage in patients with a creatinine increase of at least $0.3 \mathrm{mg} / \mathrm{dL}$ within 48 hours and/or a 1.5 or more increase in creatinine from baseline. This new classification may help initiate specific therapy at an earlier stage and increase the chance for recovery. This classification is also more appropriate to identify any kind of kidney injury within a wide spectrum of causes of acute, chronic, and acute-on-chronic kidney diseases in cirrhosis. However, even if the patients are identified at an earlier stage, the revised classification does not clearly differentiate those who may benefit from medical therapies of HRS (that is, terlipressin or noradrenaline) [11] from those who may not. In addition, this classification does not help address the important issue of reversibility after liver transplantation.

In most Western countries, the Model for End-Stage Liver Disease (MELD) score determines priority for allocation in liver transplantation. The higher the MELD score, the faster the access to transplantation. Since creatinine is one of the three components of the MELD score (along with bilirubin and international normalized ratio) [12], the proportion of patients undergoing liver transplantation with renal insufficiency has significantly increased in the MELD era [13]. The rate of posttransplant chronic renal failure has also increased with a 5 -year cumulative incidence that may exceed 20\% [14]. Decrease in post-transplant GFR is an independent predictor of mortality [14]. Finally, the number of combined liver and kidney transplantations has also increased with declining outcomes, raising the issue of overuse and misuse in combined transplantation [15].

Overall, circulatory changes in cirrhosis necessarily have a deleterious impact on the course of any chronic kidney disease, regardless of the cause and mechanisms. A challenging issue is to determine more accurately the potential for improvement with liver transplantation alone, by reversing hyperkinetic state, in order to better identify those who need a combined liver and kidney transplantation and those who do not. In theory, HRS is a functional disorder that is fully reversible with liver transplantation. However, as discussed above, a number of patients with HRS have intrinsic kidney changes that may not improve after transplantation. Therefore, another issue is to better identify the subgroup of HRS patients who are likely to rapidly develop end-stage renal failure after transplantation. These patients may justify combined transplantation. As stated by Nadim and colleagues [1], more studies are needed to clarify these points. Unfortunately, in patients who have end-stage cirrhosis complicated by HRS and who are not candidates for transplantation, therapies such as terlipressin or albumin dialysis provide only a modest survival benefit
[11]. In the majority, HRS remains a terminal event in advanced cirrhosis.

\section{Abbrevations}

GFR, glomerular filtration rate; HRS, hepatorenal syndrome; MELD, Model for End-Stage Liver Disease.

Competing interests

The authors declare that they have no competing interests.

Published: 6 March 2012

\section{References}

1. Nadim MK, Kellum JA, Davenport A, Wong F, Davis C, Pannu N, Tolwani A, Bellomo R, Genyk Y: Hepatorenal syndrome: the $8^{\text {th }}$ International Consensus Conference of the Acute Dialysis Quality Initiative Group. Crit Care 2012, 16:R23.

2. Gines P, Schrier RW: Renal failure in cirrhosis. N Engl J Med 2009, 361:1279-1290.

3. Gines P, Guevara M, Arroyo V, Rodes J: Hepatorenal syndrome. Lancet 2003, 362:1819-1827.

4. Moreau R, Lebrec D: Acute renal failure in patients with cirrhosis: perspectives in the age of MELD. Hepatology 2003, 37:233-243.

5. Arroyo V, Ginès P, Gerbes AL, Dudley FJ, Gentilini P, Laffi G, Reynolds TB, RingLarsen $\mathrm{H}$, Schölmerich J: Definition and diagnostic criteria of refractory ascites and hepatorenal syndrome in cirrhosis. International Ascites Club. Hepatology 1996, 23:164-176.

6. Salerno F, Gerbes A, Gines P, Wong F, Arroyo V: Diagnosis, prevention and treatment of hepatorenal syndrome in cirrhosis. Gut 2007, 56:1310-1318.

7. Trawale JM, Paradis V, Rautou PE, Francoz C, Escolano S, Sallee M, Durand F, Valla D, Lebrec D, Moreau R: The spectrum of renal lesions in patients with cirrhosis: a clinicopathological study. Liver Int 2010, 30:725-732.

8. Francoz C, Prie D, Abdelrazek W, Moreau R, Mandot A, Belghiti J, Valla D, Durand F: Inaccuracies of creatinine and creatinine-based equations in candidates for liver transplantation with low creatinine: impact on the model for end-stage liver disease score. Liver Transp/ 2010, 16:1 169-1177.

9. Francoz C, Glotz D, Moreau R, Durand F: The evaluation of renal function and disease in patients with cirrhosis. J Hepatol 2010, 52:605-613.

10. Mehta RL, Kellum JA, Shah SV, Molitoris BA, Ronco C, Warnock DG, Levin A: Acute Kidney Injury Network: report of an initiative to improve outcomes in acute kidney injury. Crit Care 2007, 11:R31.

11. Moreau R, Durand F, Poynard T, Duhamel C, Cervoni JP, Ichaï P, Abergel A, Halimi C, Pauwels M, Bronowicki JP, Giostra E, Fleurot C, Gurnot D, Nouel O, Renard P, Rivoal M, Blanc P, Coumaros D, Ducloux S, Levy S, Pariente A, Perarnau JM, Roche J, Scribe-Outtas M, Valla D, Bernard B, Samuel D, Butel J, Hadengue A, Platek A, et al:: Terlipressin in patients with cirrhosis and type 1 hepatorenal syndrome: a retrospective multicenter study. Gastroenterology 2002, 122:923-930.

12. Wiesner R, Edwards E, Freeman R, Harper A, Kim R, Kamath P, Kremers W, Lake J, Howard T, Merion RM, Wolfe RA, Krom R; United Network for Organ Sharing Liver Disease Severity Score Committee: Model for end-stage liver disease (MELD) and allocation of donor livers. Gastroenterology 2003, 124:91-96.

13. Gonwa TA, McBride MA, Anderson K, Mai ML, Wadei H, Ahsan N: Continued influence of preoperative renal function on outcome of orthotopic liver transplant (OLTX) in the US: where will MELD lead us? Am J Transplant 2006, 6:2651-2659.

14. Sharma P, Welch K, Eikstadt R, Marrero JA, Fontana RJ, Lok AS: Renal outcomes after liver transplantation in the model for end-stage liver disease era. Liver Transp/2009, 15:1142-1148.

15. Locke JE, Warren DS, Singer AL, Segev DL, Simpkins CE, Maley WR, Montgomery RA, Danovitch G, Cameron AM: Declining outcomes in simultaneous liver-kidney transplantation in the MELD era: ineffective usage of renal allografts. Transplantation 2008, 85:935-942.

doi:10.1186/cc11207

Cite this article as: Francoz C, Durand F: A new look at renal dysfunction in the cirrhotic patient. Critical Care 2012, 16:118. 